\title{
Manufacturing of microCarb critical optical components and their impact on the instrument's performances
}

Sébastien Lopez, Yann Gaeremynck, Laurent Georges, Matthieu Castelnau, Elodie Cansot, et al.

Sébastien Lopez, Yann Gaeremynck, Laurent Georges, Matthieu Castelnau, Elodie Cansot, Véronique Pascal, "Manufacturing of microCarb critical optical components and their impact on the instrument's performances," Proc. SPIE 11852, International Conference on Space Optics - ICSO 2020, 118521R (11 June 2021); doi: 10.1117/12.2599319

SPIE Event: International Conference on Space Optics - ICSO 2021, 2021, Online Only 


\section{International Conference on Space Optics-ICSO 2020}

Virtual Conference

30 March-2 April 2021

Edited by Bruno Cugny, Zoran Sodnik, and Nikos Karafolas
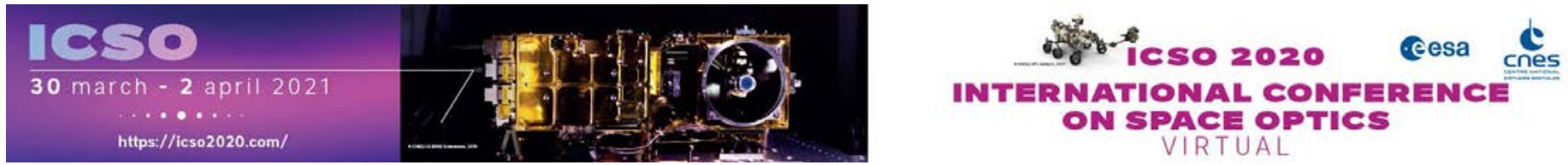

\section{Manufacturing of microCarb critical optical components and their impact on the instrument's performances}

\section{Cesa isoporecestings denes}




\title{
MANUFACTURING OF MICROCARB CRITICAL OPTICAL COMPONENTS AND THEIR IMPACT ON THE INSTRUMENT'S PERFORMANCES
}

\author{
Sébastien Lopez (a), Yann Gaeremynck (a), Laurent Georges (a), Matthieu Castelnau (b), \\ Elodie Cansot (b), Véronique Pascal (b) \\ a - Airbus D\&S France - 31, Av. des Cosmonautes - 31402 Toulouse Cedex 4- France \\ b-CNES - 18, avenue Edouard Belin - 31401 Toulouse Cedex 9
}

\begin{abstract}
Able to monitor very precisely $\mathrm{CO} 2$ gases concentration in the atmosphere (better than $1 \mathrm{ppm}$ ), MicroCarb is a CNES mission which instrument is a passive Short Wave InfraRed spectrometer that will help scientists to better understand the planet's major ecosystems and gain a clearer picture of its carbon budget at regional scales. Reaching such a monitoring precision means that the instrument has very stringent requirements especially in terms of radiometry, spectral filtering, spectral bands co-registration and polarization sensitivity.
\end{abstract}

The MicroCarb instrument is currently under integration at Airbus Defence and Space facilities in Toulouse (France). It is based on an innovative concept permitting the acquisition of the spectral bands using a single split-pupil telescope, spectrometer and detector. Spectral bands multiplexing is obtained by the grating, each band corresponding to a different diffraction order, between 15 and 40 . The split-pupil concept is characterized by 3 sets of 4 to 5 assembled prisms at entrance telescope pupil, spectrometer slit and in front of the detector, all participating to the complex spectral filtering.

All the components considered as critical for the performances of the instrument have been manufactured and are under integration: the echelle grating replicated in a $\mathrm{SiC}$ substrate, the assembled optical elements with narrow spectral filtering coatings and the Dual Babinet polarization scrambler.

In this paper we will focus on these optical components, detailing for each one how the stringent requirements of the instrument have been transposed to their specification, close to the limits of manufacturability. We will be able to present their development and achievement with respect to these specifications and how they impact the global performances of the instrument.

\section{INTRODUCTION}

Able to monitor very precisely $\mathrm{CO} 2$ gases concentration in the atmosphere, MicroCarb is a CNES mission which instrument is a passive Short Wave InfraRed (SWIR) spectrometer that will help scientists to better understand the planet's major ecosystems and gain a clearer picture of its carbon budget at regional scales.

Currently under integration at Airbus facilities in Toulouse, MicroCarb is based on an innovative concept permitting the acquisition of 4 spectral bands using a single split-pupil telescope, spectrometer and detector. Some of the mission requirements have important impacts on the manufacturing of the optical parts. Are detailed hereafter the impact on Pupil separation prisms PSP, Pupil alignment prisms PAP, grating and polarization scrambler and the way the manufacturers allowed Airbus to provide the best instrument. 


\section{OPTICAL INSTRUMENT CONCEPT}

The optical concept of MicroCarb has previously been detailed and explained (see [1]).

As a reminder, the concept optimizes the volume of the instrument by imaging 4 spectra of a same surface on ground in a single detector, reducing the optical parts to a single telescope and a single spectrometer. The principle is a split-pupil telescope coupled with a double-pass spectrometer which includes a reflective grating operating in quasi-littrow configuration.

As the target is to use a single detector, it is mandatory to separate the different spectra in the spatial direction. This is simply obtained with 4 slits in the telescope focal plane: one per spectral band. It is thus necessary to realign the 4 slits on the same location on ground, which is made at telescope's pupil level. The principle is illustrated in Fig. 1, considering 3 points on the focal plane of the telescope for easier representation. Fig. 1(a) is a common single-pupil telescope: the three points are separated in the telescope field. Fig. 1(b) shows the same system with an independent pupil per focal point, the three points still see different points on ground but it can be compensated by inserting a dedicated prism in each sub-pupil as represented in Fig. 1(c).

These prisms are called "Pupil separation prisms" or PSP.

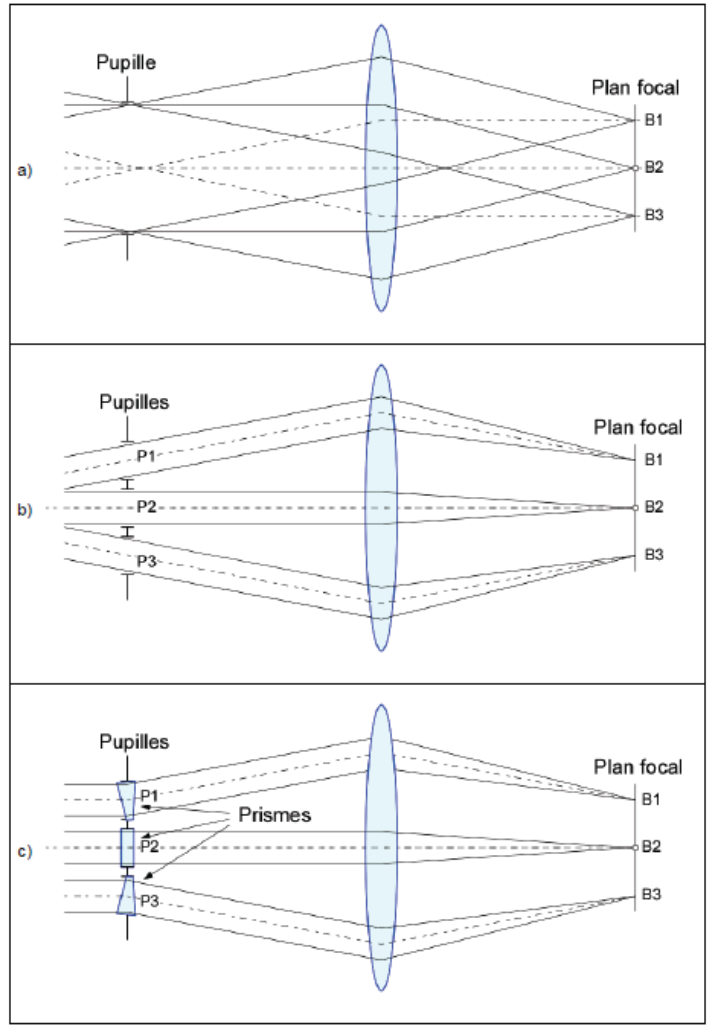

Figure 1: Principle of pupil separation (b) and LOS compensation with prims (c) in comparison with a typical instrument (a)

This configuration easily allows integrating a dedicated sub-pupil for an imager through the same telescope, separated from the spectrometer path by a beam splitter located in the telescope's exit pupil. Contrarily it increases the telescope's volume by multiplication of the pupils, but it is not a problem for MicroCarb as the pupils are of a few square millimeters. 
The different PSPs are splitting the field along the across-track direction (ACT, spatial direction on the detector) and the form and disposition of the pupils are optimized to reduce the telescope's full aperture. As shown in Fig. 2 , they are mainly separated in the along-track (ALT, spectral direction in the detector) direction.

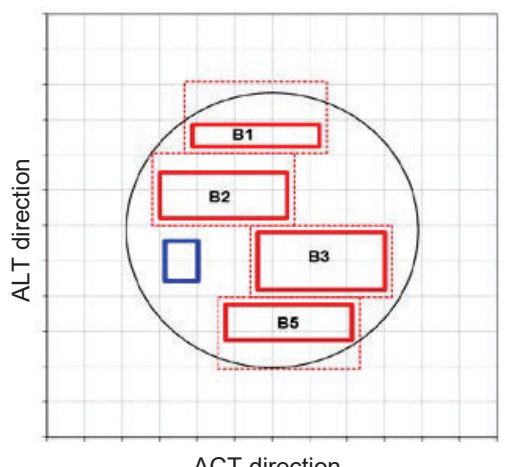

Figure 2: Telescope sub-pupils organization

The spectrometer part of the instrument is based on the use of a multiplexed echelle diffraction grating. It is common to the 4 spectral bands, each diffracting in the same direction but at different diffraction orders.

In order to reach the simplest and compacts configuration, this grating is placed in a Littrow-type double-pass reflective spectrometer. Thus the ACT magnification is 1 and the spacing of the imaged spectral bands is identical to the slits spacing. Fig. 3 illustrates the spectrometer design.

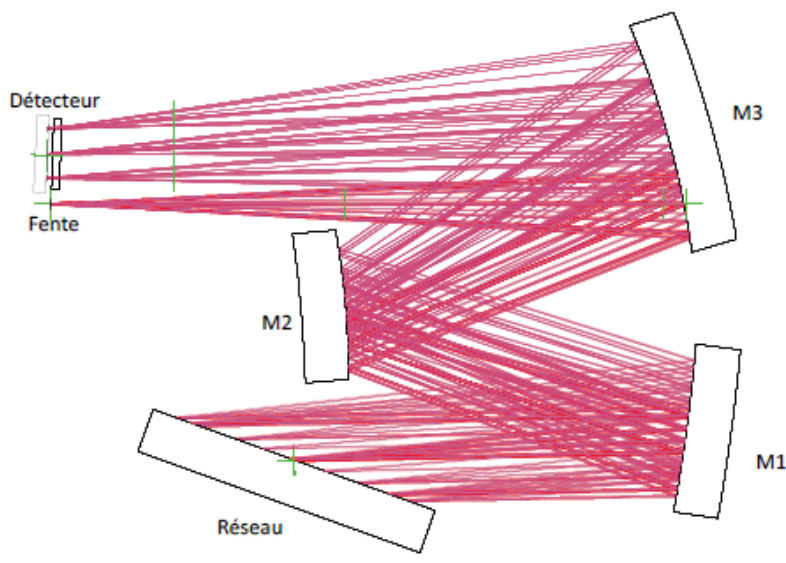

Figure 3: Principle of a double-pass spectrometer with multiplexed grating

For a typical spectrometer with one pupil common to the spectral bands, this pupil is imaged on the grating in order to reduce its dimensions. It is particularly important for a multiplexed echelle grating for which the use of high diffraction orders and important incidence are mandatory. Due to the split pupil configuration of the telescope with apertures separated in the ALT direction, this advantage is lost unless the separation is compensated close to the slit plane with other prisms. These "Pupil Alignment Prisms" or PAP modify the pupil imaging properties of the instrument to superimpose all the sub-pupils on the grating plane. The principle is illustrated in Fig. 4, one prism after each slit compensates the ALT position of its sub-pupil in order to align it on the spectrometer optical axis and thus reduce the useful surface of the grating. 


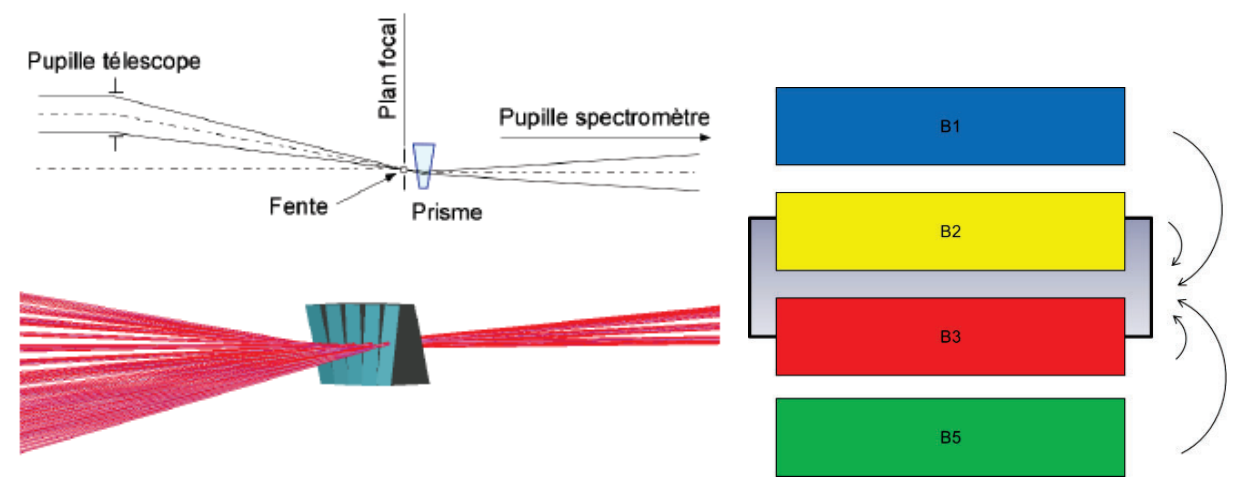

Figure 4: Principle of pupils images re-alignment on the grating plane. The ALT position of each sub-pupil is compensated with one prism per slit

MicroCarb instrument also includes a scanning device to be operated in 4 modes : Nadir, Glint, Target and Scan mode. A polarization scrambler is added in-between the Scan mirror and the telescope.

The final design of MicroCarb instrument is shown in Fig. 5.

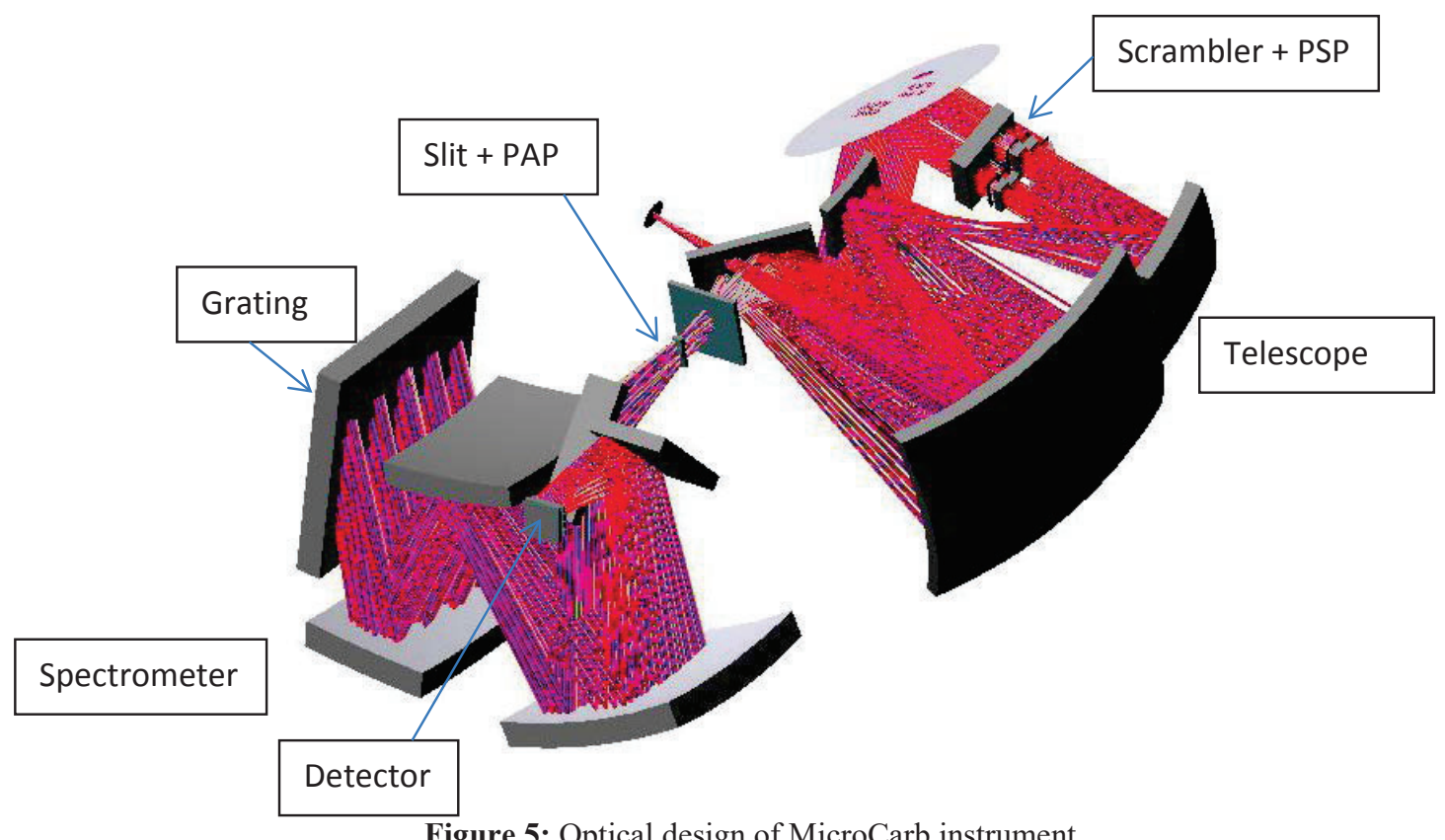

Figure 5: Optical design of MicroCarb instrument.

\section{IMPACT OF MISSION REQUIREMENT ON THE OPTICAL MANUFACTURING}

The main requirements of MicroCarb instrument is probably the ones concerning the Instrument Spectral Response Function (ISRF). These requirements have an important impact on the optical design and optics manufacturing as the choice of an echelle grating, the slit size, etc... We chose in this paper not to deal with ISRF requirements in particular as it has already been the subject of a publication (see [2]).

The other requirements which are of most importance for the mission are:

- The polarization sensitivity requirement 
- $\quad$ The inter-band co-registration

- $\quad$ The knowledge of ISRF shape

- $\quad$ And of course the spectral sampling

The polarization sensitivity goal is specified to be less than $0.1 \%$ in Glint mode $(0.25 \%$ as a threshold $)$ and $0.7 \%$ in other modes ( $5 \%$ as a threshold). This is a very demanding requirement which has a direct impact on the grating as it is the most polarization sensitive element of the optical design. But even with major efforts on the grating design and realization, there is no way to answer this requirement without a polarization scrambler and a carefully designed scanning device.

Fig. 6 show the theoretical and toleranced polarization sensitivity of the instrument as a function of scan mirror orientation, with zoom on the Glint zone where the specification is more critical. The polarization scrambler considered is a Dual Babinet Polarization Scrambler (DBPS) placed on the entrance pupil of the telescope, after the scanning device. One can see that the commitment of Airbus cannot be better than $0.3 \%$ in one extremity of the Glint area for bands B1 and B4. Thus the instrument can be marginally out of specification at Glint level even if the polarization sensitivity is close to the goal specification for other pointing directions ( $1 \%$ for a goal specified at $0.7 \%$ ).

The analyses show that the polarization sensitivity performance is mainly driven by:

- $\quad$ The reflective coatings performance of the scanning device, especially for B1,

- The grating polarization sensitivity, especially for B1 and B2

- $\quad$ The DBPS, especially for B3 and B4.

The manufacturing accuracy of MicroCarb's DBPS is more demanding than for other spectrometers due to the multi-pupil telescope. For example, contrarily to a DBPS centered on a common pupil, an error on one Babinet angle also induces a variation on the delta-thickness between the two prisms of this Babinet,which has an impact on the depolarization performance.

Thus the final performance is directly related to the manufacturers capabilities.
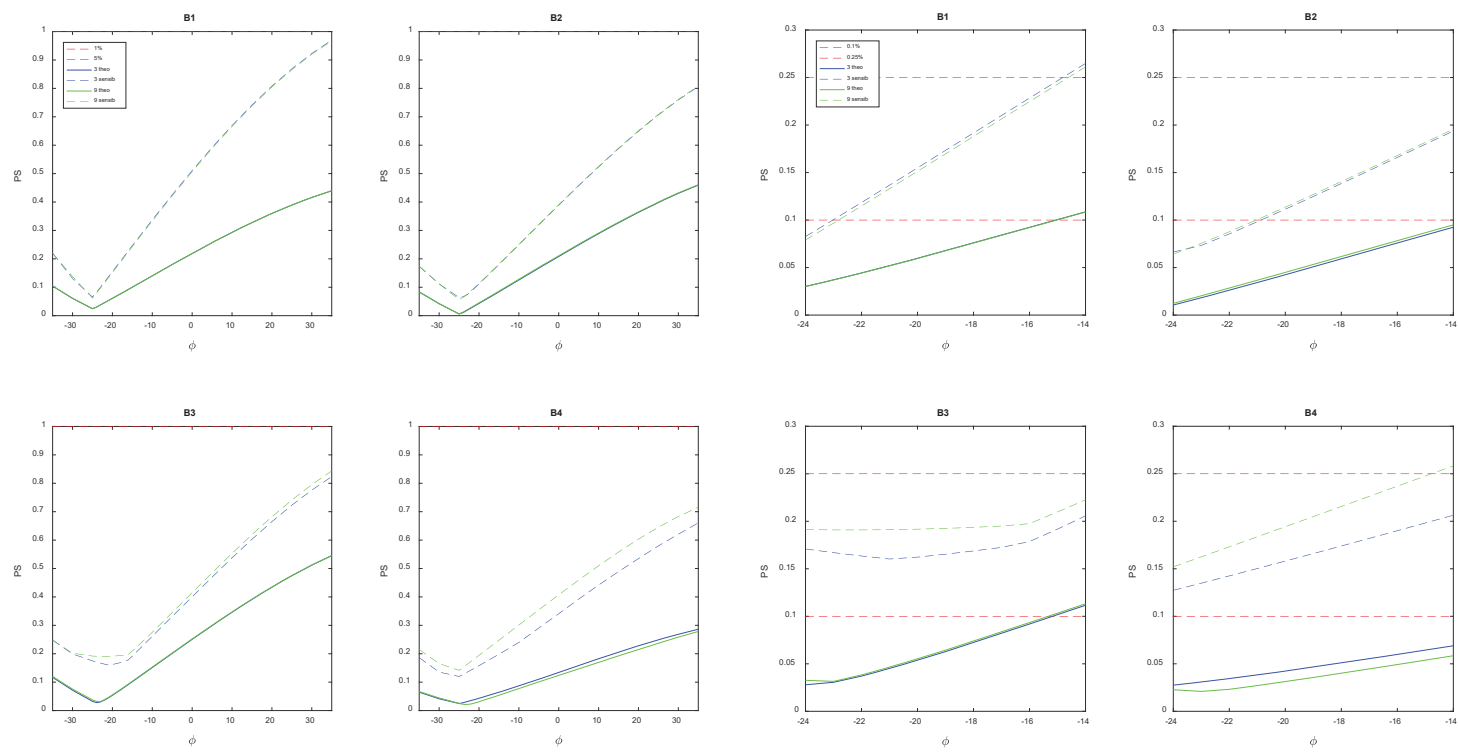

Figure 6: Polarization sensitivity as a function of scan angle per spectral band, for the complete scan range (left) and zoomed in Glint mode (right). Solid line for theoretical performance and dashed line for tolerance performance 
The spectral sampling is not a direct requirement for the mission but comes from the resolution and mandatory spectral band to acquire. B1 mandatory spectral band has to be imaged on 1014 of the 1024 pixels of the detector, which is a tight tolerance for alignment and component manufacturing. It has also to be considered that the spectrometer operates at cold temperature but is integrated at ambient.

Consequence of this parameter, the ruled grating will be preferably replicated on a substrate of same material than the rest of the spectrometer structure: $\mathrm{SiC}$, and the impact of temperature on the grating's density shall be taken into account on its specification.

The inter-band co-registration is usually not problematic ACT for a common slit spectrometer. But it becomes of first importance with a split-pupil telescope. With one slit imaged on several detectors it is easily possible to co-register the pixels in the spatial direction whereas our optical concept imposes severe tolerances on both PSP and slit manufacturing. In addition, the DBPS generates a diamond pattern variable with the scene direction of polarization, of course dependent of the spectral band. The overall co-registration budget is thus linked to the polarization sensitivity requirement and the allocations for PSP and slit manufacturing are reduced.

The most severe PSP in silicon shall have both wedge and parallelism tolerances in the range of $+/-35 \mu \mathrm{rad}$. In addition, if the thickness of the PSP is not demanding, the clocking of each PSP with respect to the other shall be better than $+/-170 \mu \mathrm{rad}$. To be considered taking into account the size of the PSP around 20x8.5x5 mm3.

Another important requirement for the instrument is the knowledge of the ISRF shape in the spectral direction. This requirement is of major importance for the $\mathrm{CO} 2$ retrieval and indirectly has an incidence on the PAP requirement. This requirement imposes to reduce as possible the inter-band defocus and thus imposes the optical path difference from one to another PAP. This requirement is translated on the PAP specification with a maximum inter-channel defocus smaller than $10 \mu \mathrm{m}$ in equivalence of slit position. This severe requirement is to be balanced with the relaxed requirements in wedge and parallelism accuracy $(+/-8.5 \mathrm{mrad})$ and prisms orientation ( $1 \mathrm{mrad}$ tilts and $3.5 \mathrm{mrad}$ clocking), but also the $4 \times 4 \times 2.5 \mathrm{~mm} 3$ volume of each PAP.

\section{GRATING MANUFACTURING}

The MicroCarb grating is an Echelle plane grating type with low groove density and working simultaneously in several diffracted orders (40th, 24th, 19th and 15th) covering the respective B1, B4, B2, B3 MicroCarb spectral bands. A master grating has been firstly ruled to produce an optimized blazed groove profile with straight and low roughness edges and as-designed blaze and counter-blaze angles to maximize the diffraction efficiency and minimize the straylight.

As previously mentioned the spectrometer is operated at cold temperature but aligned at ambient temperature. Airbus has a strong heritage of $\mathrm{SiC}$ instruments and quickly saw the interest for a grating replicated on a $\mathrm{SiC}$ substrate and organized a predevelopment together with Horiba beginning of phase B2. This predevelopment concluded that the replica is possible on a raw $\mathrm{SiC}$ substrate but failed in a CVD substrate as it can be seen in Fig. 7.
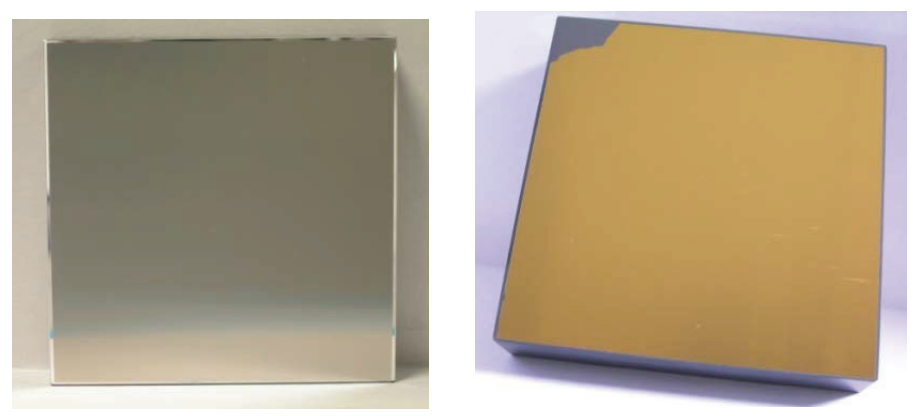

Figure 7: Replication success on raw SiC substrate (left) but failure on CVD SiC substrate (right) 
This success set off the qualification of gratings replicated on raw $\mathrm{SiC}$ substrate, qualified with success. But it also gave opportunity to measure the evolution of the grating density with temperature. A dedicated test bench has been developed in Airbus facilities and replicas on some different substrates were characterized. Fig. 8 shows a picture of the gratings, test bench and results of the characterization.
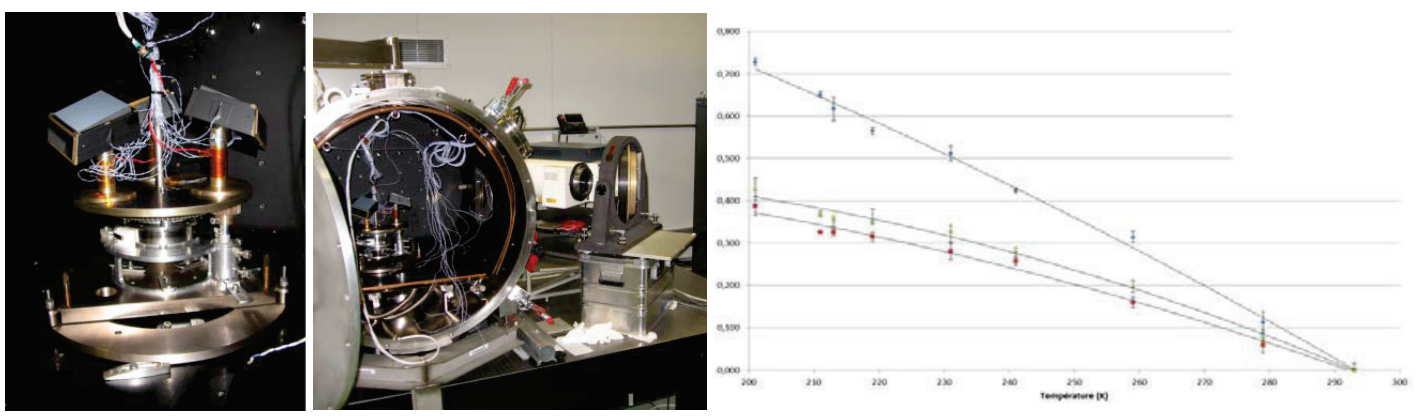

Figure 8: Characterization of grating variation of density wrt temperature. Set-up (left and center) and results (right)

Thus, the master Echelle grating with density adapted to ambient temperature has been replicated on a weight lighted Silicon Carbide substrate for the flight model, which is to our knowledge the first time for a space instrument, and coated with an Aluminum layer (Fig. 9). The efficiency and polarization sensitivity have been characterized in Horiba facilities at order 20, which is not a useful order for MicroCarb but is representative of the performances at the lower $15^{\text {th }}$ and $19^{\text {th }}$ orders and also in CNES facilities at order 40 . The two characterizations being in line with requirement, the performances at order 24 are fulfilled. Characterization at order 20 compared to theoretical curves is given in Fig. 10.
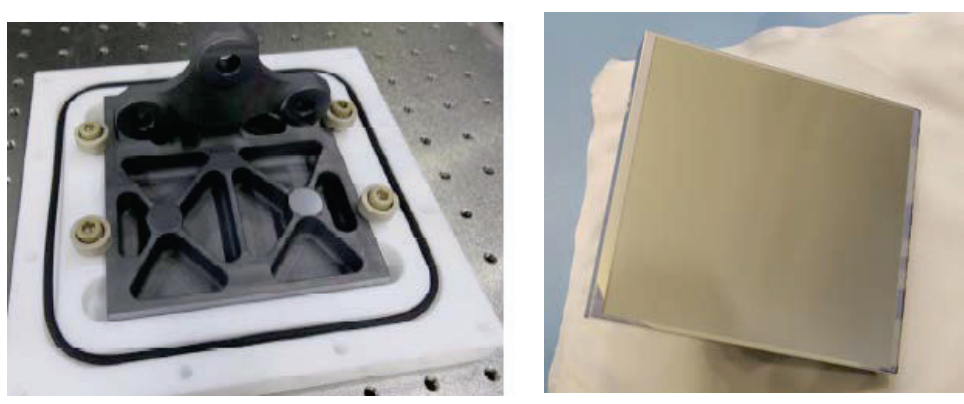

Figure 9: Pictures at delivery of back face of the grating with weightlighted SiC substrate (left) and front face of the grating with Aluminum coating (right) (c) Horiba

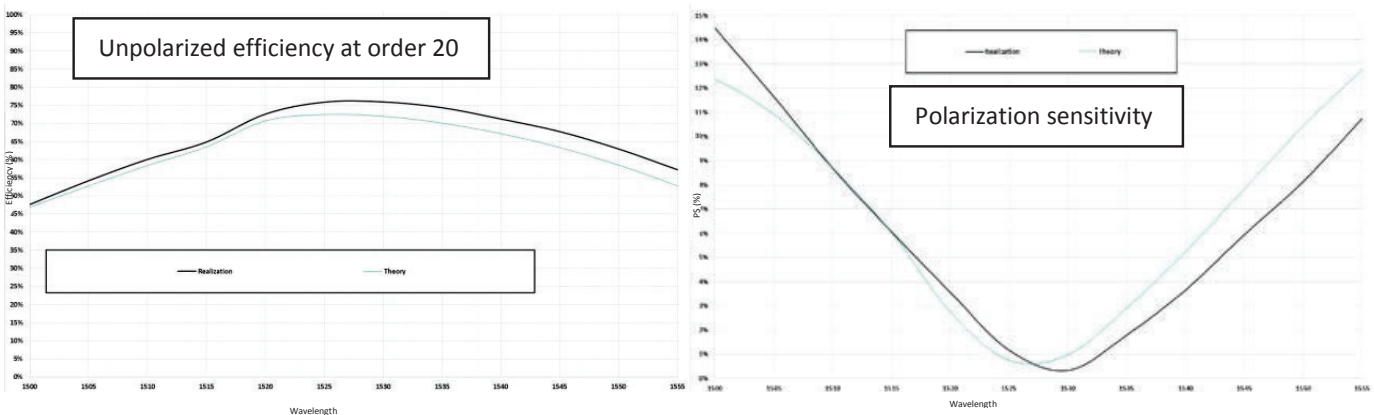

Figure 10: FM grating efficiency (left) and polarization sensitivity (right) 
The obtained polarization sensitivity is very close to the theoretical one, better than Horiba's commitment. This is of very good news for the polarization sensitivity of the complete instrument in Glint zone. No more details will be given here on the grating realization and efficiency measurements but it will probably be the main topic of a future publication.

The grooves density was specified at $61.43+/-0.11 / \mathrm{mm}$ and realized $61.433+/-0.001 \mathrm{1} / \mathrm{mm}$. This is also much better than requirement and will assure to image the complete spectral bands with the expected Spectral Sampling Interval.

\section{POLARIZATION SCRAMBLER MANUFACTURING}

The Dual Babinet polarization scrambler assembly of MicroCarb is the result of a fruitful collaboration of Airbus for the analyses and definition, Optique Fichou for the optical part manufacturing and Winlight System for the mounting design and assembly. This industrial arrangement optimizes the technological exchanges at any level:

- Analyses and definition is core business of Airbus. Its direct implication improves the definition as all the optical properties of the coatings and grating properties can be modelled to optimize the DBPS efficiency and requirements in accordance with the manufacturer's capabilities.

- Optique Fichou is leader in Europe in crystal polishing. Its implication was mandatory and its open mind during exchanges with Airbus on manufacturing processes allowed to specify the right need and to focalize on important requirements.

- Winlight System benefit from PSP definition and assembly to develop the DBPS mount. Unless this is not core business of Winlight to integrate optics which have not been manufactured internally, they answered to Airbus request with an appreciated implication for the instrument.

An example of 2 prisms of a same Babinet obtained after polishing by Fichou is given in Fig. 11. The conformity for all requirements was expected but one can see that the obtained values are much better than the strict need and reveal a strong implication to provide Airbus and CNES with the best component, so important for the mission. Fig. 11 also shows the DBPS at Fichou delivery.

\begin{tabular}{|c|c|c|c|}
\hline Désignation & Requirement & \multicolumn{2}{|c|}{ Result } \\
\hline \multicolumn{2}{|c|}{ Ensemble } & Prisme 1 & Prisme 2 \\
\hline \multicolumn{2}{|c|}{ Matière } & \multicolumn{2}{|c|}{ quartz } \\
\hline Section Xm & $44 \mathrm{~mm} \approx 0.2 \mathrm{~mm}$ & 44.148 & 44.149 \\
\hline Section $\mathrm{Ym}_{\mathrm{m}}$ & $44 \mathrm{~mm} \pm 0.2 \mathrm{~mm}$ & 44.147 & 44.148 \\
\hline Section & $44 \mathrm{~mm} \pm 0.2 \mathrm{~mm}$ & 44.150 & 44.150 \\
\hline Section & $44 \mathrm{~mm} \neq 0.2 \mathrm{~mm}$ & 44.150 & 44.143 \\
\hline Angle & $1^{1} 16^{6} 12^{\prime \prime} \pm 30^{\prime \prime}$ & $1^{\prime \prime} 16^{\prime} 11^{\prime \prime}$ & $1^{\circ} 16^{\prime} 13^{\prime \prime}$ \\
\hline Center thickness & $4 \mathrm{~mm} \pm 0.05 \mathrm{~mm}$ & 4.033 & 4.033 \\
\hline Delta thickness & $<0.005 \mathrm{~mm}$ & \multicolumn{2}{|c|}{0} \\
\hline Wedge orientation & $<12^{\prime}$ & $z^{\prime}$ & $2^{\prime} 30^{\prime \prime}$ \\
\hline Perpendicularity sides vs A & $<2^{2}$ & $\leq 30^{\prime \prime}$ & $\leq 40^{\prime \prime}$ \\
\hline Parallelism vs B & $<3^{\prime}$ & $\leq 30^{\prime \prime}$ & $\leq 30^{\prime \prime}$ \\
\hline Roughness & $<2 \mathrm{~nm}$ RMMS & conforme & Conforme \\
\hline Surface defects & $5 / 2 \times 0.05 ; 10.01 ; E 0.5$ & Conforme & Conforme \\
\hline
\end{tabular}

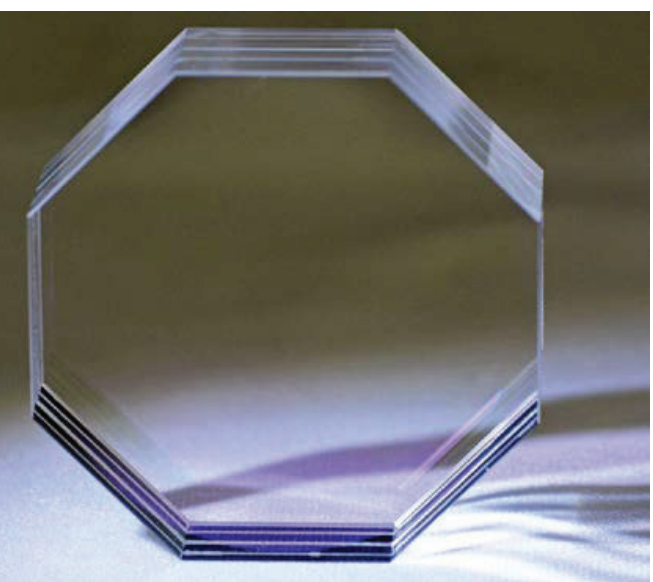

Figure 11: Comparison between requirements and realization of prisms (left) and picture of delivered DBPS $\odot$ Fichou

The DBPS is mounted in a Titanium mount designed by Winlight System. The major requirement at this level is the knowledge of the scrambler's location and orientation on the assembly. The result is a scrambler 
characterized a few microns accuracy on the assembly mechanical reference frame. Fig. 12 shows the DBPS assembly delivered by Winlight System and partially integrated in Airbus facilities.

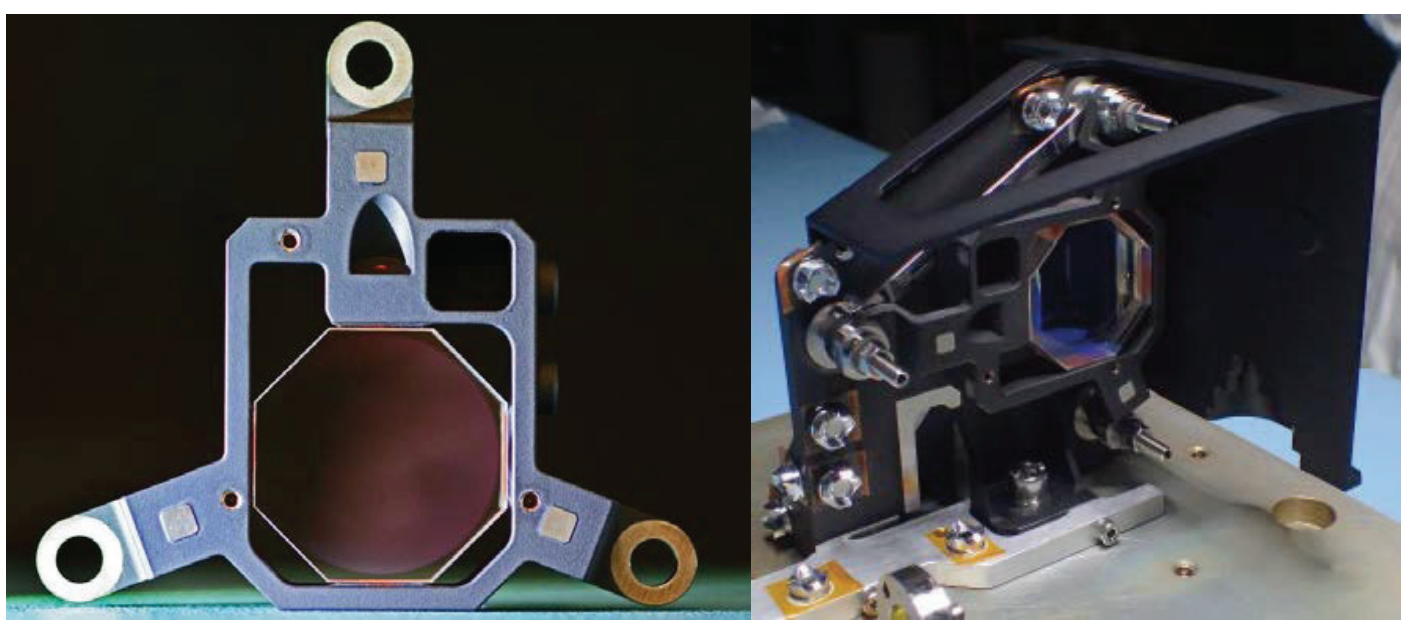

Figure 12: DBPS assembly at delivery (C) Winlight System (left) and during integration on the instrument (right)

The performance-critical DBPS assembly is a complete success, delivered in a record time with record performances thanks to implication of all the players. Completed with coating performances of the scan device also much better than simulated in section 3 , it is possible to expect a final instrument with polarization sensitivity much better than expected, closer from the theoretical curves than from Airbus commitment. We are now confident to deliver an instrument compliant with the customer's requirements with a polarization sensitivity in Glint mode smaller that $0.25 \%$.

\section{PRISMS MANUFACTURING}

The PSP and PAP manufacturing and integration were of major importance for the instrument performances, as previously mentioned. For Winlight System these sub-assemblies required huge efforts on opto-mechanical design to answer Airbus requirements. From instrumental requirements were derived prisms manufacturing and polishing constraints based on a very interesting principle of integration.

To achieve the location and orientation of the prisms together, prisms are glued on a silica barrel using silica shims to benefit from optical measurement capabilities and reach the expected accuracy. This silica barrel is then glued in a Titanium mount designed to support all the thermal and mechanical constraints. Winlight System demonstrated their capability to be a first rank furnisher for optical sub-assemblies, especially for small and accurate optical elements.

Fig. 13 shows an example of review of polishing conformity for a Silicon PSP. As an example, the prism angle specified $2.512+/-0.002^{\circ}$ would be conform if measured $2.512+/-0.0017^{\circ}$ but was measured $2.5119^{\circ}$, which is almost half the tolerance.

Fig. 14 and 15 show different steps of integration of the PSP and PAP together with the final sub-assembly as delivered. 


\begin{tabular}{|c|c|c|c|c|}
\hline \multicolumn{5}{|c|}{ W04572-210-F003-C } \\
\hline Item & Requirement & Success criteria & Result & $\mathrm{C} / \mathrm{NC}$ \\
\hline Matīerre & Silice Suprasil 300I & Silice Suprasil 3001 & Silice Suprasil 3001 & $\mathrm{C}$ \\
\hline Hauteur & $20.6 \pm 0.01 \mathrm{~mm}$ & $\begin{array}{c}20.6+0.0096 / \\
-0.0086 \mathrm{~mm}\end{array}$ & $20.603 \mathrm{~mm}$ & C \\
\hline Largeur & $8.5 \pm 0.1 \mathrm{~mm}$ & $\begin{array}{l}8.500+0.0996 / \\
-0.0986 \mathrm{~mm}\end{array}$ & $8.566 \mathrm{~mm}$ & c \\
\hline Epaisseur & $4.787 \pm 0.09 \mathrm{~mm}$ & $\begin{array}{c}4.787+0.0896 / \\
-0.0886 \mathrm{~mm}\end{array}$ & $4.847 \mathrm{~mm}$ & C \\
\hline Angle Face B/E & $85.666^{\circ} \pm 0.009^{\circ}$ & $85.666^{\circ} \pm 0.0087^{\circ}$ & $85.6631^{\circ}$ & $\mathrm{C}$ \\
\hline Angle Face B/D & $2.512^{\circ} \pm 0.002^{\circ}$ & $2.512^{\circ} \pm 0.0017^{\circ}$ & $2.5119^{\circ}$ & C \\
\hline Perpendicularité A $\perp E$ & $1<10$ arcseclA|El & $<8.5^{\prime \prime *}$ & $6.05^{\prime \prime}$ & $\mathrm{C}$ \\
\hline 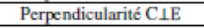 & $1<10$ arcsec|ClE $\mid$ & $<8.5^{\prime * *}$ & $0.3^{\mathrm{n}}$ & $\mathrm{C}$ \\
\hline Perpendicularité $\mathrm{B} \perp \mathrm{A}$ & $90 \mathrm{AB}=90^{\circ} \pm 7 \operatorname{arcsec} * *$ & $90^{\circ} \pm 5.5^{\prime \prime *}$ & $90^{\circ} 00^{\prime} 1.55^{\prime \prime}$ & $\mathrm{C}$ \\
\hline 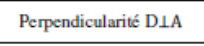 & $\begin{array}{c}90 \mathrm{AD}=(180-90 \mathrm{AB}) \\
\pm 7 \operatorname{arcsec}^{* *}\end{array}$ & $\begin{array}{l}\left(180^{\circ}-90^{\circ} 00^{\prime} 1.55^{\prime \prime}\right)= \\
89^{\circ} 59^{\prime} .58 .45^{\prime \prime} \pm 5.5^{\prime \prime *}\end{array}$ & $90^{\circ} 00^{\prime} 0.5^{\prime \prime}$ & C \\
\hline Rayon de courbure face B & $>500 \mathrm{~m}$ sur $\mathrm{ZU}$ & $>510 \mathrm{~m}$ & $1.9 \mathrm{~km}$ & $\mathrm{C}$ \\
\hline Planéité face B & $\begin{array}{c}\text { SFE }<2 \text { nm RMS sur ZU } \\
\text { (cf. plan) }\end{array}$ & $<2 \mathrm{~nm}$ RMS $* * *$ & $1.40 \mathrm{~nm}$ RMS & c \\
\hline Rayon de courbure face D & $>500 \mathrm{~m}$ sur $\mathrm{ZU}$ & $>510 \mathrm{~m}$ & $7.6 \mathrm{~km}$ & $\mathrm{C}$ \\
\hline Planéićé face D & $\begin{array}{l}\text { SFE }<2 \text { nm RMS sur ZU } \\
\text { (cf. plan) }\end{array}$ & $<2 \mathrm{~nm}$ RMS $* * *$ & $1.64 \mathrm{~nm}$ RMS & C \\
\hline 1 & Toutes les faces polies & Toutes les faces polies & Toutes les faces polies & C \\
\hline Planéité face $\mathrm{A}$ & $317 \mathrm{~nm}$ PTV & $<300 \mathrm{~nm}$ PTV & $146 \mathrm{~nm}$ PTV & $\mathrm{C}$ \\
\hline Planéité face C & $317 \mathrm{~nm}$ PTV & $<300 \mathrm{~nm}$ PTV & $99 \mathrm{~nm}$ PTV & C \\
\hline Planéité face E & $317 \mathrm{~nm}$ PTV & $<300 \mathrm{~nm}$ PTV & $85 \mathrm{~nm}$ PTV & C \\
\hline Aspect face B & $5 / 2 \times 0.05 ; 1 \mathrm{~L} 0.01 ; \mathrm{E} 0.15$ & $\begin{array}{c}5 / 2 \times 0.05 ; \text { IL } 0.01 ; \\
\text { E0.15 }\end{array}$ & $\begin{array}{c}\text { Zones de } 20 \text { filoches } 2 / \text { de } \\
30 \text { à } 750 \mu \mathrm{m} \mathrm{HZU} \\
1 \text { filoche } 3 \mu \mathrm{m} / 2 \mathrm{~mm} \\
2 \text { points } 20 \mu \mathrm{m} \\
1 \text { éclat } \emptyset 150 \mu \mathrm{m} \\
\end{array}$ & c \\
\hline Aspect face D & $5 / 2 \times 0.05 ; 1 \mathrm{~L} 0.01 ; \mathrm{E} 0.15$ & $\begin{array}{c}5 / 2 \times 0.05 ; 1 \mathrm{~L} 0.01 ; \\
\text { E0.15 }\end{array}$ & 1 filoche $3 \mu \mathrm{m} / 10 \mathrm{~mm}$ & C \\
\hline Rugosité face B & $<\operatorname{lnm}$ RMS & $<0.92 \mathrm{~nm}$ RMS & $0.34 \mathrm{~nm}$ RMS & $\mathrm{C}$ \\
\hline Rugosité face D & $<\operatorname{lnm}$ RMS & $<0.92 \mathrm{~nm}$ RMS & $0.26 \mathrm{~nm}$ RMS & $\mathrm{C}$ \\
\hline Chanfreins & ch $0.2 \alpha-0.1 \times 45^{\circ}$ partout & $\begin{array}{c}\text { ch0. } 0.20 \% \\
0.1 \times 45^{\circ} \text { partout }\end{array}$ & $0.2 \times 0.2 \mathrm{~mm}$ & c \\
\hline
\end{tabular}

Figure 13: Example of polishing conformity for PSP B3 Silicon prism @
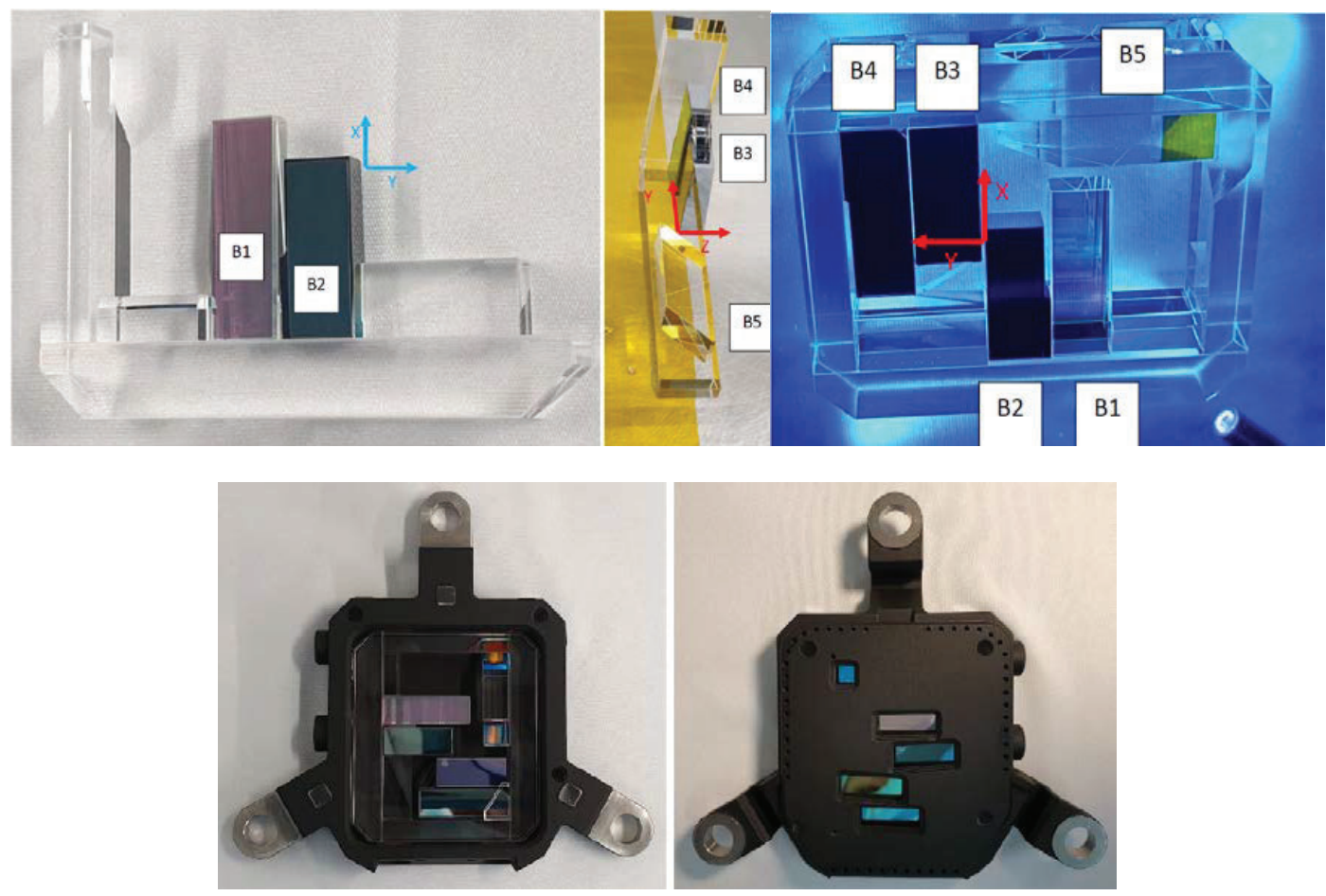

Figure 14: integration steps of the PSP from prisms gluing to final sub-assembly $\odot$ Winlight System 

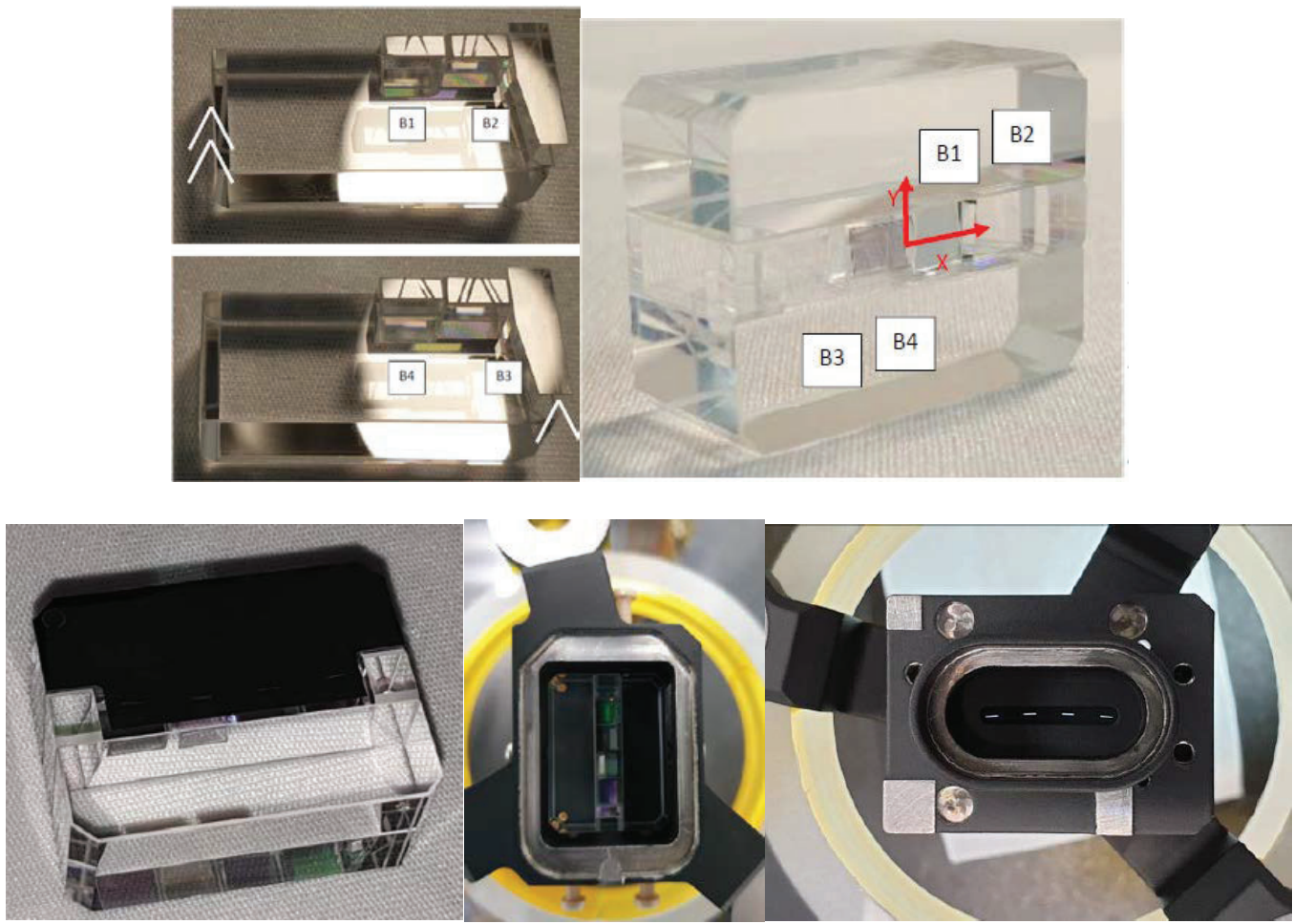

Figure 15: integration steps of the PAP from prisms gluing to final sub-assembly ${ }_{C}$ Winlight System

The achieved PSP and PAP sub-assemblies manufacturing is a success, with a limited number of RFW, and allows Airbus to be confident in responding to the CNES requirements on inter-band co-registration, smile and similarity of ISRF in spectral direction with a Gaussian.

\section{CONCLUSION}

The tight requirements of the MicroCarb instrument have been reflected on all the optical components. Some of the requirements at technology limit were identified of potential risk for the performances of the instrument. But thanks to the implication and best efforts of all the players, from the grating to the prims and polarization scrambler the delivered products are above expectations and give confidence in the final performances of the instrument.

All these components are currently under integration at Airbus facilities. For now it is Airbus role to integrate and align these components with the same best effort demonstrated by these manufacturers in order to enable the challenging monitoring of the carbon fluxes between the atmosphere and the Earth surface. 


\section{REFERENCES}

[1] F. Pasternak, Ph. Bernard, L. Georges, V. Pascal, "The Microcarb Instrument”, ICSO 2016

[2] M. Castelnau, E. Cansot, C. Buil, V. Pascal, V. Crombez, S. Lopez, L. Georges, M. Dubreuil, "Modelization and validation of the diffraction effects in the Microcarb instruments for accurately computing the Instrumental Spectral Response Function”, ICSO 2018 